Poznań

\title{
Realizacja Programu Kulturalnego Polskiej Prezydencji w Radzie Unii Europejskiej
}

Program Kulturalny Polskiej Prezydencji jest wizytówką półrocznego sprawowania przez Polskę przewodnictwa w UE. Skierowany jest zarówno do odbiorców w kraju, jak i za granicą. Wydarzenia kulturalne są częścią oficjalnych spotkań polityków lub stanowią ich tło. Zasadniczym celem programu jest promocja kraju w Europie i na świecie. Z drugiej strony program kulturalny zakłada promocję idei integracji europejskiej wśród Polaków jako obywateli państwa sprawującego półroczną prezydencję.

W Polsce, przygotowania do sprawowania prezydencji rozpoczęły się jeszcze w 2009 roku. W tym czasie też Departament Współpracy z Zagranicą Ministerstwa Kultury i Dziedzictwa Narodowego we współpracy z Narodowym Instytutem Audiowizualnym, po konsultacji z Międzyresortowym Zespołem Opiniodawczo-Doradczym ds. Promocji i Kultury opracował założenia konstruowania programu kulturalnego. Należą do nich:

a) spójność - z długoterminową strategią promocji Polski;

b) współpraca - artystów z organizacjami kulturalnymi pochodzącymi z innych państw członkowskich Unii Europejskiej i spoza UE;

c) jakość projektów, a nie ilość - każdy projekt musi mieć jasno określoną grupę odbiorców docelowych i dodatkowo powinien być dostosowany do trendów artystycznych panujących w danym państwie;

d) kompatybilność - program kulturalny powinien nawiązywać do: motta prezydencji, wytycznych na poziomie europejskim (są to m.in. Partnerstwo Wschodnie oraz Europejska Polityka Sąsiedztwa) ${ }^{1}$.

Bezpośrednim koordynatorem całego przedsięwzięcia zostało Ministerstwo Kultury i Dziedzictwa Narodowego, które wyznaczyło dwie instytucje do opracowania programu kulturalnego polskiej prezydencji. Odpowiadają one za opracowanie projektów wchodzących w skład programu oraz za sposoby ich realizacji. Jest to Narodowy Instytut Audiowizualny, który odpowiada za realizację Krajowego Programu Kulturalnego Polskiej Prezydencji oraz Instytut im. Adama Mickiewicza, który odpowiada z kolei za realizację Zagranicznego Programu Kulturalnego Polskiej Prezydencji².

Tuż przed objęciem przez Polskę przewodnictwa w Radzie UE Instytut Polski im. Adama Mickiewicza stworzył specjalny portal internetowy nawiązujący do hasła

1 Departament Współpracy z Zagranicą Ministerstwa Kultury i Dziedzictwa Narodowego: Strategiczne założenia programu kulturalnego polskiej prezydencji (data wejścia na stronę 14 września 2011).

2 http://mkidn.gov.pl/pages/pl2011/pl/agora/prezydencja.php (data wejścia na stronę 25 sierpnia 2011). 
polskiej prezydencji: Uwaga na kulturę. Jego głównym zadaniem jest promowanie twórców polskiej kultury i dostarczanie wielu rzetelnych informacji na temat wydarzeń kulturalnych mających miejsce w kraju i za granicą. Portal zawiera również biografie artystów, eseje, opisy dzieł itp. ${ }^{3}$ Ponadto Instytut współpracując z polskimi placówkami dyplomatycznymi w Berlinie, Paryżu, Brukseli, Londynie, Madrycie, Moskwie, Mińsku, Kijowie, Tokio, Pekinie promuje polską kulturę i jej dorobek na świecie.

Instytut Mickiewicza przygotował także sześć filarów programu kulturalnego, które zostały zatwierdzone do realizacji przez Radę Programową ds. Oprawy Kulturalnej Polskiego Przewodnictwa Radzie w UE w 2010 roku . Do filarów tych należą: I Culture Puzzle, Guideto to the Poles, Czesław Miłosz Audiobook, Planeta Lem, Karol Szymanowski, I Culture Orchestra.

I Culture Puzzle to Warsztat Nowoczesnego Rzemiosła, projekt który skupia ponad 200 ochotników z Europy i Azji. Pod przewodnictwem projektantki mody Moniki Jakubiak artyści mają rozważać (zarówno w teorii, jak i w praktyce) rolę rzemiosła we współczesnej kulturze ${ }^{5}$.

Przewodnik do Polaków to próba pokazania Europie i światu, jakie czynniki kształtowały mentalność Polaków. Za pośrednictwem pięciu projekcji filmowych obejmujących takie wydarzenia jak: muzyka rockowa, moda, himalaizm, obyczaje seksualne oraz dziecięce zabawy i zabawki przedstawiono polską drogę do wolności ${ }^{6}$.

Oglądając filmy widzowie mogą poznać wybitnego himalaistę - Jerzego Kukuczkę, wysłuchać fragmentów koncertów zespołów punkowych i rockowych (Tilt, Dezerter), a tym samym poznać atmosferę jarocińskiego festiwalu. Przedstawiane w projekcjach filmowych trendy przejawiające się zarówno w zachowaniu, jak i kreacji czy też w ubiorze były szczególną formą buntu wobec władzy w latach 70-tych i 80-tych.

Czesław Milosz Audiobook to prezentacja twórczości polskiego noblisty, który w tym roku skończyłby 100 lat (dlatego też rok 2011 ogłoszony został w Polsce rokiem Miłosza). W ramach projektu przedstawiono dorobek poety, tłumacząc jego wiersze w 10 językach i prezentując je w kilkunastu krajach (Japonii, Francji, Belgii, Wielkiej Brytanii, Ukrainie). Twórczość poety dotyka bieżących europejskich spraw, takich jak: polityka sąsiedztwa, Partnerstwo Wschodnie. Dlatego szczególnie dziś, w dobie kryzysu społeczeństwa międzykulturowego, jego myśli przepełnione tolerancją, pochwała dialogu, przenikaniem się kultur wydają się być szczególnie istotne i potrzebne.

Wielki pisarz XX wieku był i do dziś jest uznanym autorytetem nie tylko w Polsce i na Litwie, ale na całym na świecie. Jego dzieła mają wartość ponadnarodową, nie tylko europejską. Zdaniem Andrzeja Franaszka ${ }^{7}$ (biografa Miłosza) jego życie w pewnym

3 www.culture.pl (data wejścia na stronę 15 sierpnia 2011).

4 http://www.iam.pl/pl/dzialalnosc/prezydencja.html (data wejścia na stronę 20 sierpnia 2011).

$5 \mathrm{http} / / /$ www.iam.pl/pl/dzialalnosc/prezydencja/i-culture-puzzle.html (data wejścia na stronę 20 sierpnia 2011).

${ }_{6} \mathrm{http}: / /$ www.iam.pl/pl/dzialalnosc/prezydencja/przewodnik do polaków.html (data wejścia na stronę 20 sierpnia 2011).

${ }^{7}$ Andrzej Franaszek w 2011 roku wydał biografię Czesława Miłosza. Zbierał materiały do tej biografii przez przeszło dziesięć lat - w Polsce i na Litwie, we Francji i w Ameryce. Dotarł do wszystkich, którzy mogli o Miłoszu powiedzieć coś istotnego, spenetrował archiwa w Beinecke Library i Maisons-Laffitte, prześledził obfitą korespondencję poety. Napisana przez niego biografia noblisty 
sensie objęło prawie całe poprzednie stulecie, czego daje on wyraz w swej twórczości i dlatego zarówno sam Miłosz, jak i jego twórczość przedstawia dla nas taką wartość ${ }^{8}$.

Był on świadkiem i obserwatorem wielu istotnych wydarzeń, które odmieniły losy Europy i świata: I i II wojny światowej, rewolucji bolszewickiej, holocaustu, wyboru kardynała Wojtyły na papieża, rozwoju ruchu „Solidarność”, upadku komunizmu, wejścia Polski do NATO, negocjacji akcesyjnych z Unią Europejską. Dlatego też dla zjednoczonej Europy i jej problemów Miłosz - podróżnik, badacz, mieszkaniec pogranicza dobrze wpisuje się w rolę ,przewodnika” po Europie, natomiast dla Polaków jego osoba i twórczość stała się sposobem prezentacji Polski za granicą.

Planeta Lem to impresja Teatru Biuro Podróży, która powstała w oparciu o twórczość innego wybitnego literata polskiego - Stanisława Lema. Autorzy projektu analizują rozwój cywilizacji i technologii oraz poszukują miejsca dla człowieka w tej przestrzeni. Zdaniem Pawła Szkotaka - reżysera spektaklu, pisząc o wynalazku autor powinien przede wszystkim pokazać jak nowe technologie mogą wpływać na człowieka. Dlatego też artyści z poznańskiej grupy teatralnej ukazująjak nowoczesna technologia zmienia człowieka: „,nasz humanoidalny potomek będzie nie tylko inaczej wyglądał, zmienią się też jego relacje rodzinne i społeczne. Przyspieszenie technologiczne umożliwia kreowanie i zaspokajanie potrzeb, a także stwarza praktyczne i nieograniczone możliwości kontroli i perswazji. Tęsknota za sacrum, fantastyczne decorum, marzenie o lepszym świecie powodują że dzisiaj science-fiction stało się jedynym już możliwym rezerwuarem idei romantycznych, powszechnie rozumianych"'. Spektakl zaprezentowany został m.in. w Londynie, Berlinie, Brukseli, Madrycie, Moskwie, Kijowie, Mińsku, Pekinie i Tokio i spotkał się z pozytywnymi reakcjami światowych widowni ${ }^{10}$.

Karol Szymanowski to kolejny flagowy projekt Zagranicznego Programu Kulturalnego Polskiej Prezydencji mający na celu utrwalenie obecności najwybitniejszego po Fryderyku Chopinie polskiego kompozytora w repertuarach światowych orkiestr wielkich, teatrów i oper ${ }^{11}$. W połowie października w Pekinie odbyło się sympozjum poświęcone twórczości Karola Szymanowskiego. W sympozjum, obok badaczy chińskich wzięli udział wybitni eksperci z Polski: dr Agnieszka Chwiłek z Instytutu Muzykologii Uniwersytetu Warszawskiego oraz dr Marcin Gmys, muzykolog i krytyk muzyczny z Uniwersytetu im. Adama Mickiewicza w Poznaniu ${ }^{12}$. Rozpoczął również

została wysoko oceniona. Zob. http://tygodnik.onet.pl/33,0,68221,andrzej_franaszek_laureatem_nagrody_koscielskich,artykul.html (data wejścia na stronę 18.09.2011).

8 października 2011 roku w Chopin Theatre w Chicago odbyła się debata poetów: „Może tylko podziw mnie uratuje", na temat twórczości Czesława Miłosza. Wzięło w niej udział wielu znakomitych gości, artystów, intelektualistów i poetów: Charles Simic, Philip Levine, Stephen Bart, Oren Izenberg, Clare Cavanagh, Patricia Barber, Adam Zagajewski. Obszerną relację na ten temat opublikowano w „Tygodniku Powszechnym” z 30 października 2011.

9 http://www.gazetaprawna.pl/wiadomosci/artykuly/533458,spektakl_planeta_lem_w_madrycie.html (data wejścia na stronę 30 sierpnia 2011).

$10 \mathrm{http}: / / \mathrm{m}$.onet.pl/wiadomosci/4813520,detal.html (data wejścia na stronę 20 sierpnia 2011).

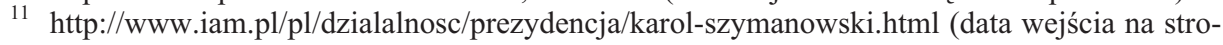
nę 20 sierpnia 2011).

$12 \mathrm{http} / /$ azja.iam.pl/en/china/international-cultural-programm-of-the-polish-eu-presidency/karol-szymanowski-music-in-beijing.html!?1lng=pl (data wejścia na stronę 19 września 2011). 
trasę koncertową zespół Szymanowski Quartet, który zawitał do Hongkongu, Tokio i wspomnianego Pekinu ${ }^{13}$.

I Culture Orchestra to inicjatywa międzynarodowa, młodych muzyków z Armenii, Azerbejdżanu, Gruzji, Ukrainy, Białorusi, Mołdawii i Polski. Artyści, za pośrednictwem muzyki, chcą promować porozumienia ponad podziałami kulturowymi. Zespół tworzy 110 muzyków. Instytut, współtworząc ponadnarodowy zespół chciał podkreślić wpływ nie tylko zachodnich, ale również wschodnich elementów kulturowych na tożsamość Europy. Orchestra występowała m.in., Berlinie, Brukseli, Kijowie, Londynie, Madrycie, a jej koncerty zostały przyjęte bardzo entuzjastycznie ${ }^{14}$. Jesienne tourne zespół zakończył koncertem w Warszawie, który odbył się 11 listopada ${ }^{15}$.

W opinii dyrektora artystycznego I Culture Orchestra Pawła Kotlaka Polska może być dumna z tego projektu. „Realizując go pokazujemy, że Polska jest pomostem między wschodem a zachodem. W sześciu krajach Partnerstwa Wschodniego odnajdujemy talenty artystyczne, a następnie umożliwiamy im rozwój swoich umiejętności i udostępniamy kontakty z najlepszymi wykładowcami z zachodnich krajów europejskich. Na tym polega wyjątkowość tego projektu"16.

Wśród innych inicjatyw realizowanych w ramach Zagranicznego Programu Polskiej Prezydencji na szczególną uwagę zasługuje ekspozycja przygotowana przez muzeum berlińskie Martin Grotious-Bau oraz zamek Królewski w Warszawie: Obok. Polska-Niemcy, 1000 lat historii w sztuce. Od 21 września 2011 do początku stycznia 2012 roku prezentowanych jest tam około 800 eksponatów, a honorowy patronat nad imprezą objęli prezydent Polski Bronisław Komorowski oraz prezydent RFN Christian Woolf. Już podczas otwarcia wystawy minister Kultury i Dziedzictwa Narodowego Bogdan Zdrojewski podkreślił, iż jest ona efektem współpracy ponad 200 instytucji z Polski i Niemiec, tym samym podkreślił on rozmach tego przedsięwzięcia.

Ekspozycja przedstawia kluczowe postaci początków sąsiedztwa Polski i Niemiec (św. Wojciecha, Rycheza, Wit Stwosza, Mikołaja Kopernika). Podkreśla wspólnotę losów polsko-niemieckich na przykładzie rozwoju miast polskich zakładanych na prawie magdeburskim (Kraków, Gdańsk). Na wystawie ukazano także dzieje zakonu krzyżackiego, a na potrzebę wystawy wypożyczono obrazy Jana Matejki - Bitwa pod Grunwaldem i Hołd pruski. Nawiązano także do okresu II wojny światowej, prezentując dzieła filmowe Andrzeja Wajdy oraz rzeźby Aliny Szapocznikow. Autorzy wystawy przedstawiają także współczesną wizję stosunków polsko-niemieckich. Zarysowali ją Piotr Uklański, Mirosław Bałka oraz Wilhelm Sasnal.

Kolejnym ważnym, wydarzeniem kulturalnym wpisanym w Zagraniczny Program Kulturalny Polskiej Prezydencji jest ekspozycja obrazów polskiego malarza i autora filmów - Wilhelma Sasnala, która miała miejsce 16 października bieżącego roku w WhiteChappell Gallery w Londynie. Laureat prestiżowej Europejskiej Nagrody Sztuki

13 http://www.pwm.com.pl/Muzyka_Karola_Szymanowskiego_w_Chinach (data wejścia na stronę 14 10.20110).

$14 \mathrm{http} / /$ kultura.onet.pl/muzyka/owacja-na-stojaco-dla-iculture-orkiestra,1,4900417, artykul.html (data wejścia na stronę 8 listopada 2011).

15 http:www.mkidn.gov.pl/pages/posts/mazowiecko-warszawskich-2465.php (data wejścia na stronę 13 listopada 2011).

16 www.tvp.gdansk.pl (data wejścia na stronę 5 października 2011). 
Współczesnej im. Vincenta van Gogha przedstawił w londyńskiej galerii 60 obrazów m.in., Tsunami (2011), Częstochowa (2010), Palestyńczyk (2010), Bez tytułu (2010) ${ }^{17}$.

Ekspozycja dzieł Sasnala została wysoko oceniona przez prasę brytyjską „,The Guardian” oraz „Independent”,

Za realizację Krajowego Programu Kulturalnego Polskiej Prezydencji odpowiada Narodowy Instytut Audiowizualny. Jest on pomysłodawcą hasła Uwaga na kulturę. Praktyczna realizacja hasła polskiej prezydencji sprowadza się do potraktowania kultury jako narzędzia zmiany społecznej - Art. for Social Change.

W jednym z wywiadów prasowych dyrektor Narodowego Instytutu Audiowizualnego Michał Merczyński w następujący sposób tłumaczył intencje animatorów projektu: ,,poprzez kreatywne działanie, postrzeganie siebie i własnej aktywności w szerszym kontekście, można potraktować kulturę i sztukę jako wartości sprawcze, zakorzenione w realnym świecie i podejmujące z nim dyskusję [...] Sztuka może być generatorem zmiany [...] kultura nie jest formą spędzania wolnego czasu czy też bezrefleksyjną rozrywką, jest elementem życia i integralną częścią procesu społecznego" "19.

Spośród najważniejszych imprez realizowanych w ramach Krajowego Programu Kulturalnego Prezydencji na szczególną uwagę zasługuje koncert skrzypcowy, który odbył się 1 października w Lusławicach - w budowanej siedzibie Europejskiego Centrum Muzyki im. Krzysztofa Pendereckiego. W tym roku impreza wpisana została w obchody Międzynarodowego Dnia Muzyki. W trakcie tzw. Koncertu Przyszłości można było usłyszeć nie tylko muzykę patrona Centrum - Krzysztofa Pendereckiego, ale również utalentowanych artystów z Polski: skrzypka Dariusza Przybylskiego oraz wiolonczelistki - Weroniki Ratusińskiej, której towarzyszył najmłodszy profesor sztuk muzycznych w Polsce - Tomasz Strahl.

Zgodnie $\mathrm{z}$ intencjami inicjatorów projektu, ideą budowanego od 2005 roku Europejskiego Centrum Muzyki jest poszukiwanie i inspirowanie młodych muzyków $\mathrm{z}$ całego świata. W tym roku w Lusławicach zaprezentowali się głównie utalentowani polscy kompozytorzy. Już od kilku lat realizowany jest projekt: „Młodzi kompozytorzy w hołdzie Fryderykowi Chopinowi”. Wyłonił on 13 już uzdolnionych kompozytorów, którzy przez 4 lata mieli możliwość nagrywania swoich utworów, które następnie prezentowane były na festiwalach krajowych i międzynarodowych.

W opinii Krzysztofa Pendereckiego, dzięki Centrum utalentowani artyści z Polski nie będą musieli „,tułać się po świecie, aby móc doskonalić swój warsztat”"20. Przeznaczone głównie dla młodych talentów Centrum ma być miejscem spotkań wykonawców i kompozytorów z mistrzami w tej dziedzinie ${ }^{21}$. Obiekt obejmuje ponad 10 tysięcy metrów kwadratowych powierzchni. Centrum jest dla mieszkańców okolic Tarnowa olbrzymim wyzwaniem i szansą na promocję regionu w Europie i na całym świecie.

\footnotetext{
17 Prace Wilhelma Sasnala omawia Piotr Kosiewski w „Tygodniku Powszechnym ” z 6 listopada $2011 \mathrm{r}$.

$18 \mathrm{http} / /$ kultura.gazeta.pl/kultura/1,114530,10499503,Sasnal_podbija_LondynBrytyjska_prasa_pozytywnie.html (data wejścia na stronę 20.10.2011). Zob. także, www.polityka.pl/kultura/aktualnoscikulturalne/1521236,2,sasnal-i-richter-w-londynie.read (data wejścia na stronę 6.11.2011).

$19 \mathrm{http}: / /$ wroclaw.gazeta.pl/wroclaw/ (data wejścia na stronę 8.09.2011).

$20 \mathrm{http} / / /$ tarnów.naszemiasto.pl/artykul/galeria//1105219 (data wejścia na stronę 11 październik 2011).

$21 \mathrm{http}: / /$ www.e-teatr.pl/en/artykuly/124758.html (data wejścia na stronę 12 październik 2011).
} 
Innym przedsięwzięciem realizowanym w ramach Krajowego Programu Kulturalnego jest wystawa zorganizowana przez Centrum Kultury w Krakowie i Narodowy Instytut Audiowizualny: Polowanie na awangardę. Zakazana sztuka i III Rzeszy. Ekspozycja ma na celu pokazanie dzieł artystów prześladowanych przez nazistów w latach 1933-1945, m.in., Maxa Ernsta, Hansa Eislera, Emila Nolde, Otto Freundlicha, Kurta Weilla, Bruno Schulza, Melchiora Wańkowicza, Jana Gotarda, Jonasza Sterna.

Po dojściu Adolfa Hitlera do władzy w 1933 roku narodowi socjaliści w Niemczech kontrolowali wszelkie przejawy życia, w tym artystycznego zarówno swoich obywateli, jak i ludów z krajów podbitych. Izba Kultury Rzeszy, na której czele stanął Joseph Goebbels krytykowała ówczesne trendy artystyczne: dadaizm, surrealizm, kubizm, a gloryfikowała prosty realizm determinowany wyższością rasy aryjskiej. W opinii organizatorów wystawy: ,połączenie sztuki, literatury i muzyki uzmysławia jak ogromny nacisk totalitarna władza kładła na to by oczyścić ówczesną kulturę z wszelkich niezgodnych z nazistowska doktryną przejawów"22.

Większość eksponatów znajdujących się na wystawie Polowanie na awangardę. Zakazana sztuka i III Rzeszy pochodzi m.in., z nadreńskich kolekcji LVR Landmuseum w Bonn, Max Ernst Museum w Brühl, ze zbiorów prywatnych dr Gerharda Steinera w Olpe, Fundacji na rzecz Sztuk Prześladowanych, zbiorów sztuki i literatury Kunstmuseum Mülheiman der Ruhr, niemieckich archiwów i bibliotek oraz z polskich kolekcji Muzeum Sztuki w Łodzi, Muzeum Okręgowego w Tarnowie, Muzeum Zagłębia w Będzinie, Muzeum Żydowskiego Instytutu Historycznego w Warszawie ${ }^{23}$. Organizatorzy wystawy, mając na uwadze „trudną historię” próbowali pokazać, iż sposób traktowania twórców jest najlepszą miarą wolności społeczeństwa.

Kolejnym ważnym wydarzeniem realizowanym w ramach Krajowego Programu Polskiej Prezydencji był 3 festiwal im Josepha Conrada, który odbył się w Krakowie w dniach 2-6 listopada 2011. Festiwal, uznawany za jedną z ważniejszych imprez literackich w Europie, w tym roku zatytułowany został: „W poszukiwaniu utraconych światów". Do Krakowa zjechało wielu znakomitych gości, m.in., Michel Huelbeque, David Grossman, Steve Sem-Sandberg, Eva Hoffman, Manuela Gretkowska, Marek Bieńczyk, Janusz Głowacki. Roberto Calasso ${ }^{24}$.

Imprezę zainaugurowała opera dla dzieci zatytułowana Itamar spotyka królika. Wyreżyserowana przez izraelskiego kompozytora Yoniego Rechtera, do tekstu izraelskiego pisarza Dawida Grossmanna była zręcznie przedstawioną metaforą opisującą współczesne skomplikowane relacje izraelsko-palestyńskie. Spektakl doskonale wpisywał się w motto Kongresu $W$ poszukiwaniu utraconych światów. Zdaniem uczestników, z jednej strony wyrażał tęsknotę za pokojem i równowagą ${ }^{25}$, z drugiej odwoływał się do osobistej tragedii literata, który w II wojnie libańskiej z 2006 roku stracił dwudziestoletniego syna.

${ }^{22} \mathrm{http}: / /$ esensja.pl/varia/galeria/tekst.html?id=13007 (data wejścia na stronę 2 listopada 2011).

${ }^{23} \mathrm{http} / / /$ benjaminmoore.pl/aktualnosci/wydarzenia/polowanie-na-awangarde.html (data wejścia na stronę 25 października 2011).

${ }^{24}$ Sylwetki gości festiwalu przybliżył czytelnikom m.in., „Tygodnik Powszechny”. Zob. Szerzej, „Tygodnik Powszechny”, z 10 lipca, 11 i 30 września oraz 30 października 2011.

25 http://tygodnik.onet.pl/33,0,71114,2,artykul.html (data wejścia na stronę 26.11.2011). 
Przez 5 dni odbyło się ponad 40 spotkań, którym przyświecał szczytny cel: „łączyć uznane z mniej znanym, popularne z elitarnym, a przede wszystkim dbać o wysoką jakość literatury, której należy się niepodzielna uwaga" ${ }^{26}$. Impreza spotkała się z dużym zainteresowaniem słuchaczy, którzy mieli jedną z niewielu okazji, aby porozmawiać z pisarzami, otrzymać od nich autograf czy zrobić wspólne zdjęcie. W opinii organizatorów, festiwal rozwija się bardzo dynamicznie. „Zaczynaliśmy 5 lat temu od kilkudziesięciu pisarzy. Teraz mamy 5 dni, 50 festiwalowych spotkań, dyskusji, pokazów filmowych, wystaw, spektakli, koncertów, przeszło stu gości z Polski i ze świata, od USA przez Argentynę, Anglię, Francję, Włochy, Holandię, Szwecję, Szwajcarię, Izrael, Białoruś, Indie)"27.

Punktem kulminacyjnym Krajowego Programu Kulturalnego polskiej prezydencji był Europejski Kongres Kultury, który odbył się w dniach 8-11 września we Wrocławiu. Zorganizowany on został przez Ministerstwo Spraw Zagranicznych RP we współpracy z Ministerstwem Kultury i Dziedzictwa Narodowego oraz Narodowym Instytutem Audiowizualnym. Imprezę współorganizowało miasto Wrocław, a współfinansowała Komisja Europejska. Na czas imprezy powołano Komitet Honorowy i Radę Kongresu.

Do stolicy Dolnego Śląska przyjechali artyści i intelektualiści z całego świata, m.in., Gianni Vattimo, Fatos Lubonja, Sara Arrhenius, Jan Fabre, Brian Eno, Olivero Toscani, Johny Greenwood, Krzysztof Wodiczko, Zygmunt Bauman, Andrzej Wajda, Zbigniew Libera.

Jeszcze przed rozpoczęciem Kongresu, zaproszonych gości powitał prezydent Miasta Wrocławia Rafał Dutkiewicz. W mowie powitalnej nawiązał do koncepcji amerykańskiego ekonomisty Richarda Floridy zawartej w książce The rise of Creative Cass, który przekonywał, że najszybciej będą rozwijać się miejsca, które zaoferują mieszkańcom wysoki standard życia, swobodę realizowania siebie oraz ciekawe rozrywki. Według Floridy miejsca te skupią tym samym najbardziej kreatywne jednostki (naukowców, liderów mody, pisarzy, redaktorów, inżynierów, informatyków), które staną się podstawą rozwoju regionów i miast. Zdaniem prezydenta Wrocławia takim miastem jest właśnie Wrocław: „Wierzymy w otwartość. Ona buduje i pozawala tworzyć. Otwartość jest sprzężona z tolerancją, rozumiana jako wyrozumiałość wobec cudzych wierzeń, poglądów, kultury choćby różniły się od naszych. Ale tolerancja jest pusta, jeśli nie ma oparcia w tożsamości. Tożsamość jest dopełnieniem dla tolerancji. To dwa słowa klucze, którymi usiłujemy wypełnić Wrocław, a do sukcesu przedsięwzięcia jak powietrza potrzebujemy Kultury"28.

Kongres gościł ponad 250 intelektualistów i artystów z całego świata. W trakcie 3 dni odbyło się 13 debat, zrealizowano ponad 100 interdyscyplinarnych projektów. Łącznie, we wszystkich kongresowych wydarzeniach wzięło udział ponad 200 tysięcy

26 „Magazyn Literacki” i „Tygodnik Powszechny” (dodatek specjalny), W poszukiwaniu utraconych światów, Kraków 2011, s. 4.

27 G. Jankowicz, M. Markowski, P. Mucharski, Festiwal Conrada jest wasz!, „Tygodnik Powszechny" z 13 listopada 2011, s. 34.

$28 \mathrm{http}: / /$ www.culturecongress.eu/whycongress/why_congress_president-dutkiewicz (data wejścia na stronę 11 września 2011). 
uczestników, w tym 550 wolontariuszy oraz dwudziestu siedmiu ministrów kultury Unii Europejskiej. Ponadto do współpracy z organizatorami zaangażowało się blisko 100 organizacji pozarządowych.

Motto przewodnie Kongresu sformułował polski socjolog Zygmunt Bauman, czerpiąc z poglądów i dorobku literatów i znanych na świecie filozofów: Georga Steinera oraz Hansa Georga Gadamera. W licznych rozmowach odbywających się podczas Kongresu przekonywał, że zadanie Europy, a nawet jej misja sprowadza się do przekazania wszystkim sztuki uczenia się wszystkich od wszystkich. Podczas Kongresu wielokrotnie podkreślał wyjątkowość różnorodnej etnicznie językowo i społecznie Europy. Przestrzegał - idąc śladem Steinera - „że Europa zginie, jeżeli nie podejmie walki o swoje języki, lokalne tradycje i autonomię społeczną. Jeżeli zapomni, że Bóg tkwi w szczegółach" 29 .

Równocześnie Bauman, w swych rozważaniach nawiązywał do innego apologety zjednoczonej Europy - Gadamera sugerując, że stąd być może bierze się ta szczególna przewaga Europy, która mogła i musiała nauczyć się sztuki życia z innymi ${ }^{30}$. „Inny”, przekonywał dalej Bauman w Europie mieszkał w zasięgu wzroku i na wyciagnięcie ręki. Inny jest tu najbliższym sąsiadem, a więc Europejczycy muszą negocjować warunki tego sąsiedztwa pomimo dzielących ich odmienności i różnic.

Bauman sugerował także, że warunkiem decydującym o rozwiązaniu problemów współczesnego świata jest „pogodna solidarność”’31. Dlatego też powinniśmy szukać natchnienia we wspólnym dziedzictwie europejskim, które odnajdujemy u starożytnych Greków. W dyskusjach toczonych podczas wrocławskiego spotkania Bauman nawiązywał m.in., do Wojny peloponeskiej ateńskiego polityka Tukidydesa.

Często powoływał się też na Gadamera, który definiował przyjaźń jako ,zdolność do życzliwego względem siebie odnoszenia się niezależnie od dzielących różnic i do pomagania sobie nawzajem z powodu tych różnic [...] Abyśmy byli zdolni i skłonni do życzliwości i uczynności bez wyrzekania się wyjątkowości - a jednocześnie niedopuszczania by ta wyjątkowość oddaliła ich od siebie lub zwróciła przeciw sobie”,32.

„Dlatego też współżycie z «Innymi», kontynuował socjolog, powinno polegać na lepszym poznaniu się i zrozumieniu, tłumaczeniu i czytaniu o «Innych». Ileż to wszyscy zyskalibyśmy mądrości, a nasze współżycie uroku, na przeznaczeniu części unijnych funduszy na finansowanie przekładów członkowskiego pisarstwa. [...] Przekonany jestem osobiście, że byłaby to najlepsza bodaj inwestycja w przyszłość Europy i powodzenia jej misji” - podsumował socjolog ${ }^{33}$.

Do najciekawszych, spektakularnych przedsięwzięć artystycznych oraz performance zrealizowanych podczas wrocławskiego Kongresu należy zaliczyć: m.in., multimedialny projekt Future Perfect prezentowany na wrocławskiej Fontannie przez Briana Eno, Projekt „Emergency Room, którego kuratorem był Thierry Geoffrey, Instalację

29 Cyt. za Z. Bauman, zob. G. Steiner, The idea of Europe, Tilburg 2004, s. 32-34.

30 Cyt. za Z. Bauman, H. G. Gadamer, Das Erbe Europa, Frankfurt 1998.

$31 \mathrm{http}: / / w w w . c u l t u r e c o n g r e s s . e u /$ europa/bauman_idea_chapter5 (data wejścia na stronę 22 września 2011).

32 Ibidem.

33 Ibidem. 
Mirosława Bałki - „Wege zur Behandlkung von Schmerzen oraz współpracę Krzysztofa Pendereckiego z Johnym Greenwoodem i Aphexem Twinem, która zaowocowała wykonaniem kompozycji: Aphex Twin „Threnody for the Victims of Hiroshima Remix, „Polymorphia Reloed, „Johny Greenwood - 48 Responses to to Polymorphia”34. Ponadto uczestnicy Kongresu bardzo entuzjastycznie przyjęli panel na temat wolności autorstwa Rubena Maesa - „Wikianarchia” oraz dyskusję na temat moderowaną przez Jacka Żakowskiego na temat finansowania kultury: „Niebezpieczne związki. Władza a kultura" ${ }^{35}$. Ponadto, w stolicy Dolnego Śląska szczególnym uznaniem cieszyły się m.in., pomysły rzeźbiarskie Mirosława Bałki, który zachęcał widzów do polemiki na temat pamięci zbiorowej Europejczyków. Artysta zbudował tzw. Pawilon Czterech Kopuł, uwzględniając m.in. jego nazistowską i komunistyczną przeszłość.

W opinii publicystki polityki Anety Kyzioł, specjalistki w zakresie wiedzy o teatrze stolica kongresu - Wrocław pasował do tego miejsca bardzo dobrze: „z jego cmentarzami pełnymi grobów, z napisami po polsku i hebrajsku"36.

Zarówno Zygmunt Bauman, jak i organizatorzy spotkania, podczas licznych dyskusji i performance często nawiązywali do hasła Uwaga na kulturę. Zgodni byli w opinii, że kultura może być czynnikiem zmiany społecznej, a tym samym może być odpowiedzią na problemy nurtujące zjednoczoną Europę (ksenofobia, nietolerancja, narodowe egoizmy). Podkreślali, że w dobie ery cyfrowej zmienia się definicja pojęcia kultura. „Jest ważna, bo uczy kreatywnego myślenia, dlatego istotna jest edukacja, kulturalna i kształtowanie kompetencji kulturalnych" ${ }^{, 37}$ - zaznaczył minister kultury i dziedzictwa narodowego - Zbigniew Zdrojewski. ,Jest skuteczną strategią rozwoju UE i naszym jej głównym kapitałem"38, dodał dyrektor generalny ds. Kultury Edukacji i Młodzieży w UE Jan Truszczyński.

Europejski Kongres Kultury był metaforą współczesnej kultury ${ }^{39}$. I choć w mediach różnie był oceniany ${ }^{40}$, trudno nie zgodzić się ze stwierdzeniem Agnieszki Wolny-Hamkało, iż to właśnie kultura, jako istotny element nie tylko integracji europejskiej, ale w ogóle życia społecznego we wszystkich jego przejawach może być początkiem nowego rozdziału w historii integracji europejskiej ${ }^{41}$.

Program Kulturalny Polskiej Prezydencji jest gigantycznym przedsięwzięciem. Polski Instytut im. Adama Mickiewicza oraz Narodowy Instytut Audiowizualny od lipca 2011 do stycznia 2012 roku zorganizują łącznie ponad 1400 imprez artystycznych,

${ }^{34}$ http://www.nina.gov.pl/prezydencja/biuro-prasowe/artykul/2011/09/22/europejski-kongres-kultury-podsumowanie (data wejścia na stronę 30 września 2011). Zob. także, Lubię mieć kontrolę, Rozmowa z Aphexem Twinem, „Polityka” z 7.09-13.09.2011.

35 A. Wolny-Hamkało, Szklanka do połowy petna, ,Tygodnik Powszechny”, 18 września 2011, s. 44.

${ }^{36} \mathrm{http}: / /$ www.polityka.pl/author=AnetaKyziol=publishDate (data wejścia na stronę 20 sierpnia 2011).

37 Ibidem.

38 Ibidem.

39 Sformułowanie Zygmunta Baumana.

40 R. Ziemkiewicz, Europejski Kongres Chattury, „Rzeczpospolita 11 września 2011; Ujazdowski krytykuje Europejski Kongres Kultury, www.gazetaprawna.pl (data wejścia na stronę 13 września 2011).

${ }^{41}$ A. Wolny-Hamkało, op. cit., s. 44. 
z których skorzystają nie tylko miłośnicy kultury, ale również miasta polskie. Organizowane imprezy kulturalne sprzyjają i sprzyjać będą integracji i promocji miast polskich w Europie i na świecie.

\section{Summary}

The implementation of the cultural program of the Polish presidency in the Council of the European Union

The main purpose of the paper is to analyze the Cultural Programme of the Polish presidency. The National Audiovisual Institute is in charge of the implementation of the Programme. The Adam Mickiewicz Institute was vested with the task of developing and implementing the Foreign Cultural Programme of the Polish Presidency. The paper analyzes and assesses selected cultural projects launched both domestically and abroad from July through November 2011. 